\title{
Does the sagittal spinal profile differ between the elderly Chinese populations with and without lumbar disc herniation?
}

\section{Jipeng Song}

Xuanwu Hospital Capital Medical University

\section{Fumin Pan}

Xuanwu Hospital Capital Medical University

Chao Kong

Xuanwu Hospital Capital Medical University

\section{Xiangyao Sun}

Xuanwu Hospital Capital Medical University

\section{Yu Wang}

Xuanwu Hospital Capital Medical University

\section{Wei Wang}

Xuanwu Hospital Capital Medical University

Shibao Lu ( $\nabla$ spinelu@163.com )

Xuanwu Hospital Capital Medical University

\section{Research Article}

Keywords: Lumbar disc herniation, Intervertebral disc degeneration, Elderly patients, Roussouly classification, Sagittal plane balance

Posted Date: August 23rd, 2021

DOI: https://doi.org/10.21203/rs.3.rs-827940/v1

License: (c) (1) This work is licensed under a Creative Commons Attribution 4.0 International License. Read Full License

Version of Record: A version of this preprint was published at Asian Journal of Surgery on March 1st, 2022. See the published version at https://doi.org/10.1016/j.asjsur.2022.03.020. 


\section{Abstract \\ Background}

The influence of spinopelvic morphology on the Chinese elderly LDH population was not clear. The purpose of this study is to explore its influence on the characteristics of lumbar disc herniation or degeneration.

\section{Methods}

212 elderly patients with LDH and 213 asymptomatic volunteers were involved. Spinal parameters were measured on full-length X-ray and compared between two populations. In herniated group, sagittal profiles were determined according to the Roussouly classification, the degenerative grades, the herniated location and the number of intervertebral lumbar disc degeneration were evaluated from the L1 to S1 on MRI scans. The differences on them among Roussouly types were analyzed.

\section{Results}

There were no significant differences in BMI, the mean value of age and sex distribution between two populations. Patients were found to have significantly smaller TK, LL, and SS than those volunteers $(p<$ $0.05)$, while contradicting observations on PT and TPA were obtained $(p<0.05)$. Roussouly type 1 and type 2 ( $50.4 \%$ and $28.7 \%$ respectively) are predominant in the LDH population and the proportion of type 1 in elderly LDH is further increased. Subjects with LDH in type 1 and 2 had lower mean herniated locations and fewer mean herniated numbers than those with type 3 and 4 .

\section{Conclusions}

Sagittal spinopelvic parameters were found to be significantly different in elderly LDH patients and asymptomatic volunteers. There were significant differences in the Roussouly distribution among different age groups of LDH. Different Roussouly subtypes have different effects on lumbar disc degeneration and herniation.

\section{Introduction}

It is well known that with an increasing age, the musculoskeletal changes and long-term external forces can lead to postural and structural changes in the shape of the spine and pelvis [1,2]. When maintaining an upright standing posture, various sagittal spinal alignments exist in different populations, which might lead to biomechanical changes, pathological changes of the intervertebral disc bearing, and further accelerate disc degeneration [3-5]. Therefore, it is essential to understand what spinopelvic morphology maybe predisposes to intervertebral disc degeneration and detect the characteristics of them. 
Lumbar disc herniation (LDH) is one of the main degenerative spinal diseases, which often occurs in the elderly population [6]. Recently, studies have investigated the characteristics of the sagittal profiles in patients with disc herniation [7, 8], and a flat back with lower lumbar lordosis, lower pelvic incidence and greater vertical orientation has been reported to be a risk factor for disc herniation [9]. Nevertheless, the sample size in those studies is relatively small and they were mainly concentrated in adolescents, the middle-aged population, and somewhat older population with a maximum average age of 63.5 years. Besides, few studies have been carried out to determine the relationship between different Roussouly types of the spine and lumbar disc herniation (LDH) in the elderly Chinese patients. Previous studies also demonstrated that patients with different spinal profiles tended to bear disc herniation in different lumbar segments $[7,9,10]$. However, the details remain lacking and more studies are necessary to be investigated.

Hence, we firstly conducted measurement of the spinopelvic sagittal parameters in 213 patients $(\geq 60$ years) with LDH and compared the results with asymptomatic volunteers. Then, we investigated the differences in the degeneration severity, the herniated location and herniated number of the lumbar segments among different Roussouly types in the elderly Chinese population. We assumed that the LDH population might have a flatter spine-pelvis shape compared to the asymptomatic volunteers. Besides, different types of the spinopelvic profiles might influence the severity, location and number of the lumbar disc degeneration.

\section{Materials And Methods \\ Participants}

We randomly included 213 patients with lumbar disc herniation (LDH) admitted to our hospital from January 2017 to May 2021. The inclusion criteria were as following:

1. Aged $\geq 60$ years old.

2. Patients with a clear diagnosis of lumbar disc herniation on MRI [11].

3. Failing $<12$ weeks physiotherapeutic or other non-operative treatment with preoperative lumbar MRIs and full spinal anteroposterior (AP) and lateral radiographs.

4. No history of spinal surgery, no spinal deformities, fracture, spondylolisthesis, tumors, trauma, isthmus, inflammation.

5. Absence of neuromuscular disorders or lower limb disease.

As a control group with matched sex distribution and BMI, 212 asymptomatic volunteers(age $\geq 60$ years)who underwent whole full spinal anteroposterior (AP) and lateral radiographs for health checkup were recruited. All data of participants above were approved by the Institutional Review Board of Xuanwu Hospital Capital Medical University.

The participant's clinical data including age, sex, body mass index (BMI), visual analogue scale (VAS) were recorded and analyzed in Table 1. Based on radiography, the two senior spinal surgeons classified 
the spine into different subtypes according to the Roussouly classification [12] Fig. 1. All subjects were assessed by one observer who was blinded to the results of other evaluations.

Table 1

Patients characteristics of the disc herniation group and Asymptomatic volunteers

\begin{tabular}{|llll|}
\hline & $\begin{array}{l}\text { Asymptomatic volunteers } \\
(\mathbf{N}=\mathbf{2 1 2})\end{array}$ & $\begin{array}{l}\text { LDH patients } \\
\mathbf{( N = 2 1 3 )}\end{array}$ & P value \\
\hline Age & $74.4 \pm 7.6$ & $75.73 \pm 8.2$ & .562 \\
\hline BMI & $24.5 \pm 2.8$ & $25.19 \pm 3.2$ & .747 \\
\hline Sex, female & $105(49.5 \%)$ & $110(51.6 \%)$ & .497 \\
\hline VAS & - & $6.72 \pm 1.53$ & - \\
\hline
\end{tabular}

\section{Radiographic evaluation}

Radiographic measurements were done by using a picture-archiving and communication system (PACS). Spinopelvic sagittal parameters were measured pre-operatively on the lateral standing full spine X-ray: in the position of hip and knee joint extension with both hands on the clavicle [13].

\section{Imaging parameters}

Radiographic sagittal parameters included in the study were as follows: thoracic kyphosis (TK), thoracolumbar kyphosis (TLK), lumbar lordosis (LL), SS (sacral slope), PT (pelvic tilt), PI (pelvic incidence), and C7-S1 sagittal vertical axis (SVA),T1 pelvic angle (TPA), PI minus LL (PI-LL). The comparison results of the parameters between the two groups are listed in Table 2. 
Table 2

Comparison of spinal parameters between LDH patients and asymptomatic volunteers

\begin{tabular}{|c|c|c|c|}
\hline & & & \\
\hline & $\begin{array}{l}\text { Asymptomatic volunteers } \\
(\mathrm{N}=212)\end{array}$ & $\begin{array}{l}\text { LDH patients } \\
(\mathrm{N}=213)\end{array}$ & $P$ value \\
\hline $\operatorname{TK}\left({ }^{\circ}\right)$ & $40.6 \pm 10.5$ & $36.1 \pm 10.2$ & .000 \\
\hline $\operatorname{TLK}\left({ }^{\circ}\right)$ & $12.2 \pm 9.7$ & $10.7 \pm 8.1$ & .091 \\
\hline $\operatorname{LL}\left({ }^{\circ}\right)$ & $47.1 \pm 12.1$ & $42.6 \pm 12.1$ & .000 \\
\hline $\mathrm{PT}\left({ }^{\circ}\right)$ & $13.3 \pm 8.1$ & $16.9 \pm 7.7$ & .000 \\
\hline $\operatorname{SS}\left({ }^{\circ}\right)$ & $32.8 \pm 8.6$ & $27.9 \pm 6.8$ & .000 \\
\hline $\mathrm{PI}\left({ }^{\circ}\right)$ & $45.8 \pm 9.8$ & $42.5 \pm 9.1$ & .000 \\
\hline SVA(cm) & $2.2 \pm 3.5$ & $4.2 \pm 3.5$ & .737 \\
\hline $\operatorname{TPA}\left({ }^{\circ}\right)$ & $11.8 \pm 7.7$ & $13.8 \pm 7.9$ & .009 \\
\hline PI-LL( $\left.{ }^{\circ}\right)$ & $-1.2 \pm 11.1$ & $-0.1 \pm 10.6$ & .279 \\
\hline
\end{tabular}

\section{Grading of lumbar disc degeneration}

The two observers assessed the degree of lumbar discs independently, according to the Pfirrmann grading system [14]. Grades 1 and 2 were classified as normal discs, while grades 3, 4, and 5 were defined as degenerated discs. The lumbar intervertebral discs from $L 1$ to $S 1$ were recorded as $1,2,3,4$, and 5, respectively. Figure 2 This value reflects the position of the discs and matches the number of discs. Besides, the extent of herniation of the lumbar intervertebral disc was summed and recorded by Arabic numerals.

\section{The number and location of lumbar disc herniation}

As described below, the degree of lumbar disc degeneration and the location of lumbar disc herniation were performed on sagittal T2-weighted MRI images from T12 to the sacrum with the participants in the supine position. The average values of them were calculated and recorded in Fig. 3.

\section{Statistical analysis}

Data collection and statistical analyses were performed using the statistical software SPSS 19. An independent-sample Student's t-test was used to compare the mean value of spinal and pelvic parameters between two groups (a group of LDH patients and the volunteers). To statistically analyze the different mechanisms in the elderly LDH patient according to the subtypes of Roussouly classification, we divided the LDH patients into two subgroups (1and 2 type group versus 3 and 4 type group). Statistical analysis was used to analyze the differences in the data of lumbar intervertebral disc 
(degeneration, the number and location of herniation) between the subtypes according to Roussouly classification in the LDH group. All P-values were two-tailed and were considered statistically significant for a value less than 0.05 .

\section{Results}

The average age of the $213 \mathrm{LDH}$ patients was $75.73 \pm 8.2$ years. 17 were excluded as they were not to belong to any of the Roussouly types. Comparison of BMI and sexual distribution in the two groups showed no significant difference.

Compared with the age-matched volunteers, the mean TK, LL, SS, and PI values for the herniated group were significantly lower, while the mean PT and TPA value was significantly greater $(P<0.01)$. No significant differences in TLK, SVA and PI-LL between these two groups were noticed. (Table 2)

The proportion of type 1 (50.4\%, the largest proportion ) and type $2(28.7 \%)$ in the elderly herniated population were significantly higher than that of the normal population and young, middle-aged herniated population. While there were only $16(7.5 \%)$ subjects and $28(13.2 \%)$ subjects belong to type 3 and 4 , respectively. (Fig. 1) The degeneration severity of the lumbar disc gradually increases from proximal to distal segments for all four types. When compared the disc degeneration degree among the four subtypes, type 3 and 4 had more severe degenerative disc changes than type 1 and 2 in the upper lumbar spine (L1-L2 through L2-L3). However, there was no difference between subtypes in the lower lumbar spine. (Fig. 2) The average herniated location in patients belonging to type 1 and 2 were $4.01 \pm 0.39,3.89$ \pm 0.52 , and higher herniated locations $(3.09 \pm 0.66,3.03 \pm 0.95)$ were found in type 3 and 4 , respectively. Meanwhile, the mean number of lumbar disc herniation segments also increased gradually from type 1 to type $4(2.17 \pm 0.95,2.26 \pm 0.85,2.61 \pm 1.34,2.94 \pm 0.85)$.

\section{Discussion}

As we all know, the center of gravity and visual balance are maintained by regulating the curvature of the spine, the posterior rotation of the pelvis, and the lower extremities [15]. Previous studies have reported that any pattern of the degenerative spine is not a static entity, which resulted from evolution [16]. As reported, the patients with LDH are characterized by a flat spine with lower LL, SS, and TK as well as higher PT, SVA and TPA [8, 17-19], which agree with our results. However, the sagittal profiles of the LDH population are significantly different from the asymptomatic volunteers with matched age and sex distribution. This can be explained by the gradual loss of lumbar lordosis with disc degeneration, which could be considered as the initiating event of the compensatory mechanism [20,21]. Consequently, patients generate a decrease of SS with an increase of PT (the backward rotation of the pelvis) to keep the balance of the "cone of economy" and to achieve a horizontal gaze. Besides, the loss of lordosis potentially leads to the anterior translation of the gravity axis (increasing SVA and TPA). Nevertheless, no significant difference was found in SVA between the two groups, indicating that the spine was still in a state of balance in the elderly LDH patients. The increase of TPA in patients with LDH indicated that the 
pelvic compensation might reach the limit, but the value was still within the normal range. In addition, the forward posture to relieve pain could also increase TPA. Our study also found that TK in the elder population was greater than that in the younger population, which is significant in both the LDH and the asymptomatic group [22, 23], confirming the tendency of more frontward postures with aging. It might be that their degenerative muscle system couldn't maintain the original curve due to muscle atrophy in the elderly population [20]. However, our study found that the TK value of herniated population was also smaller than that of the asymptomatic volunteers, which suggested that TK still had the compensatory ability to maintain the sagittal balance in the elderly population $\geq 60$ years old.

The previous study carried by Roussouly et al. [24] suggested that type 3 or type 4 lordosis (almost 70\%) were most prevalent in the asymptomatic Caucasian adult. Several studies with Asian populations also showed similar Roussouly type distributions $[23,25]$. However, some recent studies involved LDH populations had noted that subjects were mostly classified into type 1 and $2[9,10]$. In the present study, the number of type 1 and 2 cases (almost $79.1 \%$ ) increased significantly in the elderly LDH patients, while the number of type 3 and 4 cases decreased, which is consistent with the findings of the studies above. Those results indicated that a straighter shape of the spine and pelvis (type 1 and 2) might increase the risk of LDH. The possible mechanism might be that the subjects with a straighter shape shifting the vertical load distribution on the intervertebral disc and the limited compensatory capacity (the lumbar hyperextension and pelvic retroversion ) due to the short hyperlordosis and the low $\mathrm{PI}$, which will increase the injury rate to the lumbar disc resulting in disc degeneration and herniation. Another reason might be that the spinal degeneration and its compensation might alter the original Roussouly type [12]. The decrease of $L L$ in the elderly patients leads to the extensive backward tilt of the pelvis, so the subjects who now have a smooth spinal pelvic alignment may have shifted from a greater curved alignment. Emmanuelle et al. [26] also reported that the increased proportion with type 2 is shifted from type 3 in subjects with low back pain. Furthermore, our study also found that compared with the young and middle-aged LDH patients, the proportion of type 1 in the elderly population further increased and became the greatest part. This might be due to further spinopelvic degenerative evolution with aging in the elderly LDH population [12]. The decrease of LL in patients leads to the extensive backward tilt of the pelvis, so the subjects with a smooth spinopelvic alignment might show a steeper pelvis in the original shape. However, these assumptions should be confirmed in future studies. Meanwhile, a high proportion of type 1 and 2 also might be the reason why the $\mathrm{PI}$ of the herniated population is smaller than that of volunteers.

In the present study, the severity of disc degeneration is gradually increasing from the proximal to the distal segment in all subjects. Youngbae et al. [2] also concluded with similar results that the degenerative lumbar lordosis loss usually began in the lower lumbar spine. It might be related to the different segment mobility at each lumbar level and the severity of disc degeneration tended to be prevalent in the lower segments, which accounts for a greater lordosis and shows increased mobility compared the upper segments $[5,27]$. Besides, the lower segments was bore to heavier loads, which would accelerate disc degeneration [28]. As many studies suggested that the sagittal alignment is an important indicator of the disc load and pressure $[5,17,19,20]$, our study also found that compared with 
type 3 and 4, type 1 and 2 subjects have significantly lower locations and fewer lumbar disc herniation. Types 1 and type 2 spinal subtypes are characterized by the large thoracic kyphosis, the small lumbar lordosis, and the lumbar curvature is mainly in the distal lumbar spine [1], which might result in greater pressure on the distal lumbar disc. While for type 3 and 4 , a greater lumbar lordosis represents the greater mechanical stress on the posterior components instead of on the disc, which was potentially a protection to the intervertebral disc.

Several limitations still exist in this study. Firstly, multiple other factors affecting human posture need to be investigated in future longitudinal studies for more accurate evaluation, like lifestyle and occupation. Secondly, this is a retrospective study at a single center, and lacks experimental or mechanical research support and the generalisability of the results. Therefore, further detailed and longitudinal prospective multicenter studies will be needed.

\section{Conclusion}

The data collected in the asymptomatic volunteer of our study could provide a reference for planning the surgical treatment of spinal diseases in the elderly Chinese patients ( $\geq 60$ years old). Our finding suggests that elderly subjects with LDH had a flatter spinopelvic morphology characterized by a lower TK, $\mathrm{LL}$, and SS than the asymptomatic subjects. Besides, We presented that Roussouly type 1 and type 2 are predominant in the LDH population, and found a further increase in the proportion of type 1 in the elderly LDH. Significant differences in the location and the number of the herniated lumbar disc were found between type 1, 2 and type 3, 4. This study will attract more attention to elucidate the pathologic mechanics of the degenerative disc disease and to identify the elderly individuals with "high-risk anatomy" for lumbar disc herniation. As the results are further validated, this information could help in the treatment of elderly patients with degenerative spinal diseases.

\section{Abbreviations}

AP: anteroposterior

BMl: body mass index,

LL: lumbar lordosis,

LDH: lumbar disc herniation,

MRI: magnetic resonance imaging

PT: pelvic tilt,

PI: pelvic incidence,

PI-LL: PI minus LL, 
PACS: picture-archiving and communication system,

SS: sacral slope,

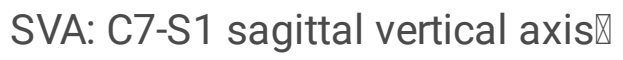

TK: thoracic kyphosis,

TLK: thoracolumbar kyphosis,

TPA; T1 pelvic angle,

VAS: visual analogue scale

\section{Declarations}

\section{Ethics approval and consent to participate}

This study was approved by the Ethical committee of Beijing Xuanwu Hospital (clinical research NO. [2018]086). Each participate ethics had a written approval and consent. All methods were carried out in accordance with relevant guidelines and regulations.

\section{Consent to Publish}

Not applicable.

\section{Availability of data and materials}

All data generated or analysed during this study are included in this published article and Supplementary material.

\section{Competing Interests}

The authors declare that the article content was composed in the absence of any commercial or financial relationships that could be construed as a potential conflict of interest.

The authors declare that neither the authors nor members of their immediate families have a current financial arrangement or affiliation with the commercial companies whose products may be mentioned in this manuscript.

\section{Funding}

This study was supported by Key Laboratory of Spine and Spinal Cord Injury Repair and Regeneration (Tongji University), Ministry of Education and by Xuanwu Hospital Science Program for Fostering Young Scholars (QNPY2020024). 
Author's contributions

Jipeng Song: Writing, Reviewing, Editing, Methodology and Data Curation.

Fumin Pan: Supervision.

Chao Kong, Xiangyao Sun, Yu Wang, Wei Wang: Supervision..

Shibao Lu: Supervision.

\section{Acknowledgements}

This study was supported by Key Laboratory of Spine and Spinal Cord Injury Repair and Regeneration (Tongji University), Ministry of Education and by Xuanwu Hospital Science Program for Fostering Young Scholars (QNPY2020024).

\section{References}

1. Chen SQ, Li QP, Huang YY, Guo AN, Zhang RF, Ye PP, Yan ZH, He JW: Different spinal subtypes with varying characteristics of lumbar disc degeneration at specific level with age: a study based on an asymptomatic population. Journal of orthopaedic surgery and research 2020, 15(1):3.

2. Kim YB, Kim YJ, Ahn YJ, Kang GB, Yang JH, Lim H, Lee SW: A comparative analysis of sagittal spinopelvic alignment between young and old men without localized disc degeneration. European spine journal: official publication of the European Spine Society, the European Spinal Deformity Society, and the European Section of the Cervical Spine Research Society 2014, 23(7):1400-1406.

3. Zárate-Kalfópulos B, Reyes-Tarrago F, Navarro-Aceves LA, García-Ramos CL, Reyes-Sánchez AA, Alpízar-Aguirre A, Rosales-Olivarez LM: Characteristics of Spinopelvic Sagittal Alignment in Lumbar Degenerative Disease. World neurosurgery 2019, 126:e417-e421.

4. Yang M, Yang C, Xu Z, Chen Z, Wei X, Zhao J, Shao J, Zhang G, Zhao Y, Ni H et al: Role of T1 Pelvic Angle in Assessing Sagittal Balance in Outpatients With Unspecific Low Back Pain. Medicine 2016, 95(9):e2964.

5. Keorochana G, Taghavi CE, Lee KB, Yoo JH, Liao JC, Fei Z, Wang JC: Effect of sagittal alignment on kinematic changes and degree of disc degeneration in the lumbar spine: an analysis using positional MRI. Spine 2011, 36(11):893-898.

6. Strömqvist F, Strömqvist B, Jönsson B, Gerdhem P, Karlsson MK: Predictive outcome factors in the young patient treated with lumbar disc herniation surgery. Journal of neurosurgery Spine 2016, 25(4):448-455.

7. Gao A, Wang Y, Yu M, Liu X: Analysis of sagittal profile and radiographic parameters in symptomatic thoracolumbar disc herniation patients. 2021, 22(1):177.

8. Yokoyama K, Tanaka H, Ito Y, Yamada M, Sugie A, Wanibuchi M, Kawanishi M: Analgesic Posture and Pelvic Morphology in Patients with Lumbar Disc Herniation. World neurosurgery 2021, 147:e411- 
e415.

9. Beck J, Brisby $\mathrm{H}$, Baranto A, Westin O: Low lordosis is a common finding in young lumbar disc herniation patients. Journal of experimental orthopaedics 2020, 7(1):38.

10. Bae J, Lee SH, Shin SH, Seo JS, Kim KH, Jang JS: Radiological analysis of upper lumbar disc herniation and spinopelvic sagittal alignment. European spine journal: official publication of the European Spine Society, the European Spinal Deformity Society, and the European Section of the Cervical Spine Research Society 2016, 25(5):1382-1388.

11. Kreiner DS, Hwang SW, Easa JE, Resnick DK, Baisden JL, Bess S, Cho CH, DePalma MJ, Dougherty P, 2nd, Fernand R et al: An evidence-based clinical guideline for the diagnosis and treatment of lumbar disc herniation with radiculopathy. The spine journal: official journal of the North American Spine Society 2014, 14(1):180-191.

12. Sebaaly A, Grobost P, Mallam L, Roussouly P: Description of the sagittal alignment of the degenerative human spine. European spine journal: official publication of the European Spine Society, the European Spinal Deformity Society, and the European Section of the Cervical Spine Research Society 2018, 27(2):489-496.

13. Horton WC, Brown CW, Bridwell KH, Glassman SD, Suk SI, Cha CW: Is there an optimal patient stance for obtaining a lateral 36" radiograph? A critical comparison of three techniques. Spine 2005, $30(4): 427-433$.

14. Pfirrmann CW, Metzdorf A, Zanetti M, Hodler J, Boos N: Magnetic resonance classification of lumbar intervertebral disc degeneration. Spine 2001, 26(17):1873-1878.

15. Lamartina C, Berjano P: Classification of sagittal imbalance based on spinal alignment and compensatory mechanisms. European spine journal: official publication of the European Spine Society, the European Spinal Deformity Society, and the European Section of the Cervical Spine Research Society 2014, 23(6):1177-1189.

16. Roussouly P, Pinheiro-Franco JL: Biomechanical analysis of the spino-pelvic organization and adaptation in pathology. European spine journal: official publication of the European Spine Society, the European Spinal Deformity Society, and the European Section of the Cervical Spine Research Society 2011, 20 Suppl 5(Suppl 5):609-618.

17. Ergün T, Lakadamyalı H, Sahin MS: The relation between sagittal morphology of the lumbosacral spine and the degree of lumbar intervertebral disc degeneration. Acta orthopaedica et traumatologica turcica 2010, 44(4):293-299.

18. Yang X, Kong Q, Song Y, Liu L, Zeng J, Xing R: The characteristics of spinopelvic sagittal alignment in patients with lumbar disc degenerative diseases. European spine journal: official publication of the European Spine Society, the European Spinal Deformity Society, and the European Section of the Cervical Spine Research Society 2014, 23(3):569-575.

19. Endo K, Suzuki H, Tanaka H, Kang Y, Yamamoto K: Sagittal spinal alignment in patients with lumbar disc herniation. European spine journal: official publication of the European Spine Society, the 
European Spinal Deformity Society, and the European Section of the Cervical Spine Research Society 2010, 19(3):435-438.

20. Barrey C, Roussouly P, Perrin G, Le Huec JC: Sagittal balance disorders in severe degenerative spine. Can we identify the compensatory mechanisms? European spine journal: official publication of the European Spine Society, the European Spinal Deformity Society, and the European Section of the Cervical Spine Research Society 2011, 20 Suppl 5(Suppl 5):626-633.

21. Niu S, Zhai X, Chen Y, Yang H, Yang C, Li M: Optimal indicators for identification of compensatory sagittal balance in patients with degenerative disc disease. BMC musculoskeletal disorders 2021, 22(1):211.

22. Zeng Z, Hai Y, Bi Y, Wang B, Liu M, Liu Y: Characteristics of sagittal spinopelvic alignment in asymptomatic Han Chinese adults. Experimental and therapeutic medicine 2018, 16(5):4107-4113.

23. Cho Y: Evaluation of Global Sagittal Balance in Koreans Adults. Journal of Korean Neurosurgical Society 2017, 60(5):560-566.

24. Roussouly P, Gollogly S, Berthonnaud E, Dimnet J: Classification of the normal variation in the sagittal alignment of the human lumbar spine and pelvis in the standing position. Spine 2005, 30(3):346-353.

25. Hu P, Yu M, Sun Z, Li W, Jiang L, Wei F, Liu X, Chen Z, Liu Z: Analysis of Global Sagittal Postural Patterns in Asymptomatic Chinese Adults. Asian spine journal 2016, 10(2):282-288.

26. Chaléat-Valayer E, Mac-Thiong JM, Paquet J, Berthonnaud E, Siani F, Roussouly P: Sagittal spinopelvic alignment in chronic low back pain. European spine journal: official publication of the European Spine Society, the European Spinal Deformity Society, and the European Section of the Cervical Spine Research Society 2011, 20 Suppl 5(Suppl 5):634-640.

27. Vedantam R, Lenke LG, Keeney JA, Bridwell KH: Comparison of standing sagittal spinal alignment in asymptomatic adolescents and adults. Spine 1998, 23(2):211-215.

28. Imagama S, Ando K, Kobayashi K, Machino M, Tanaka S, Morozumi M, Kanbara S, Ito S, Inoue T, Seki $T$ et al: Impact of pelvic incidence on lumbar osteophyte formation and disc degeneration in middleaged and elderly people in a prospective cross-sectional cohort. European spine journal: official publication of the European Spine Society, the European Spinal Deformity Society, and the European Section of the Cervical Spine Research Society 2020, 29(9):2262-2271.

\section{Figures}




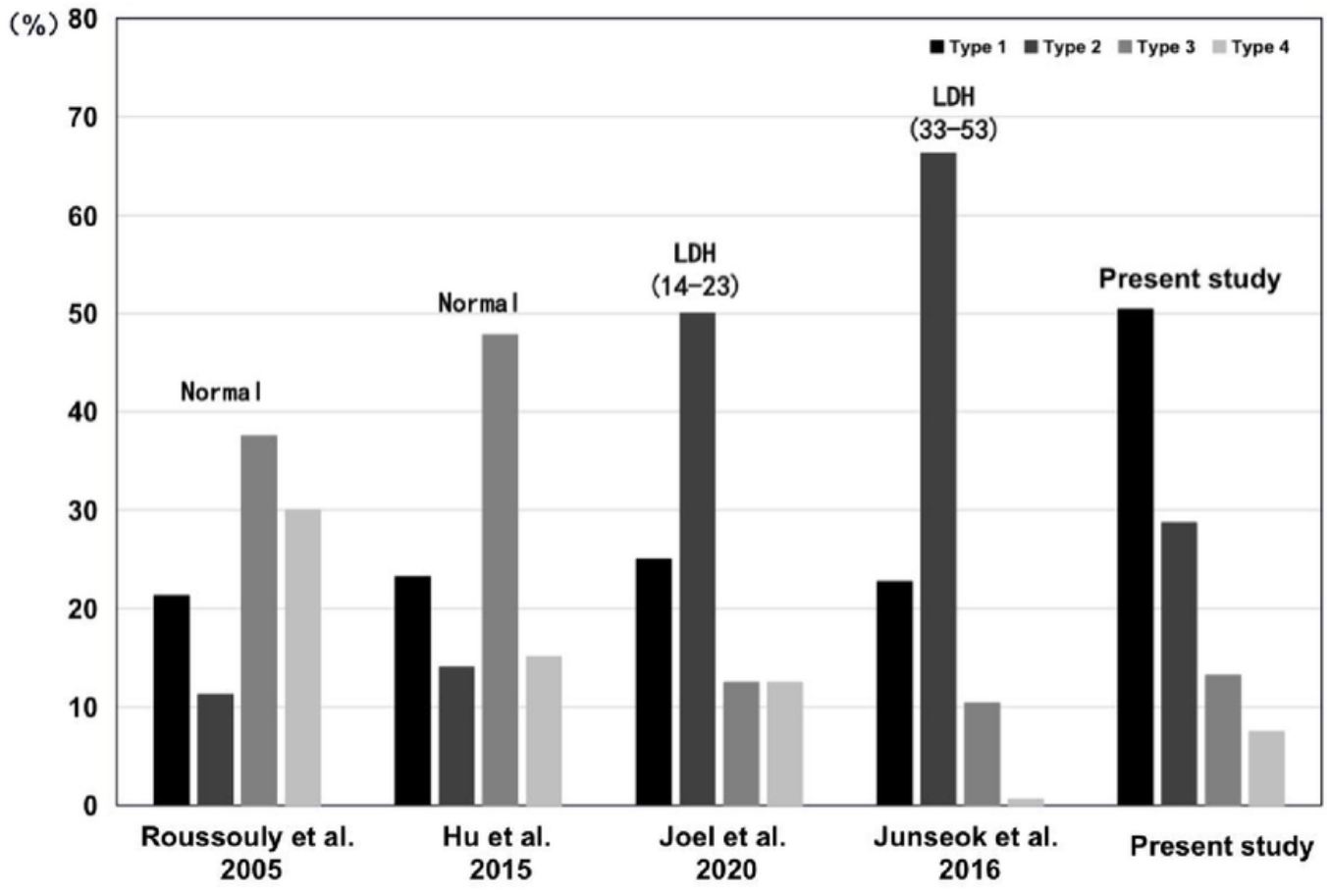

Figure 1

Distribution of four different Roussouly types among different populations. The age range of each group is displayed. 


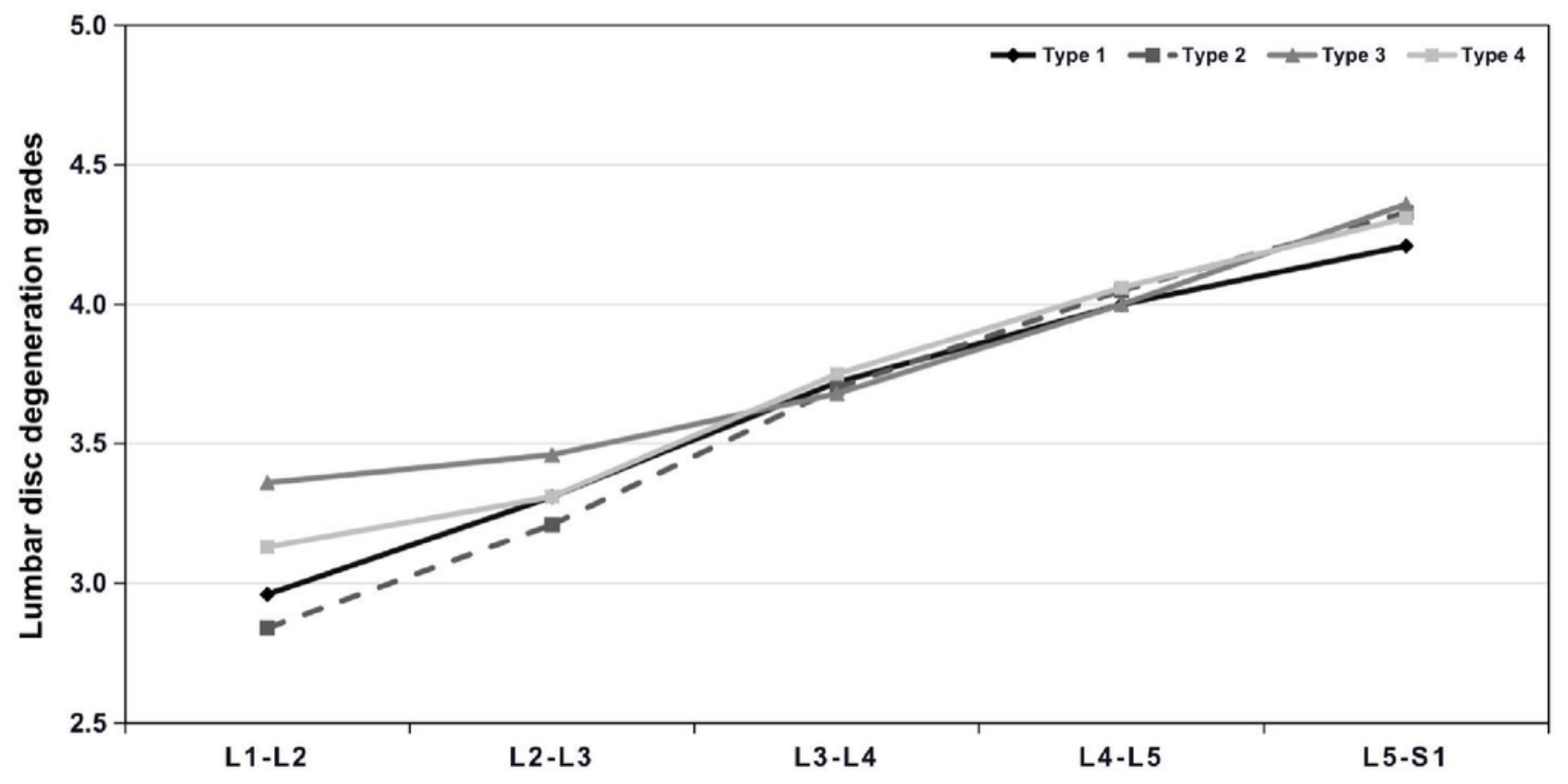

Figure 2

Disc degeneration severity of different Roussouly types of lordosis at each spinal level. 


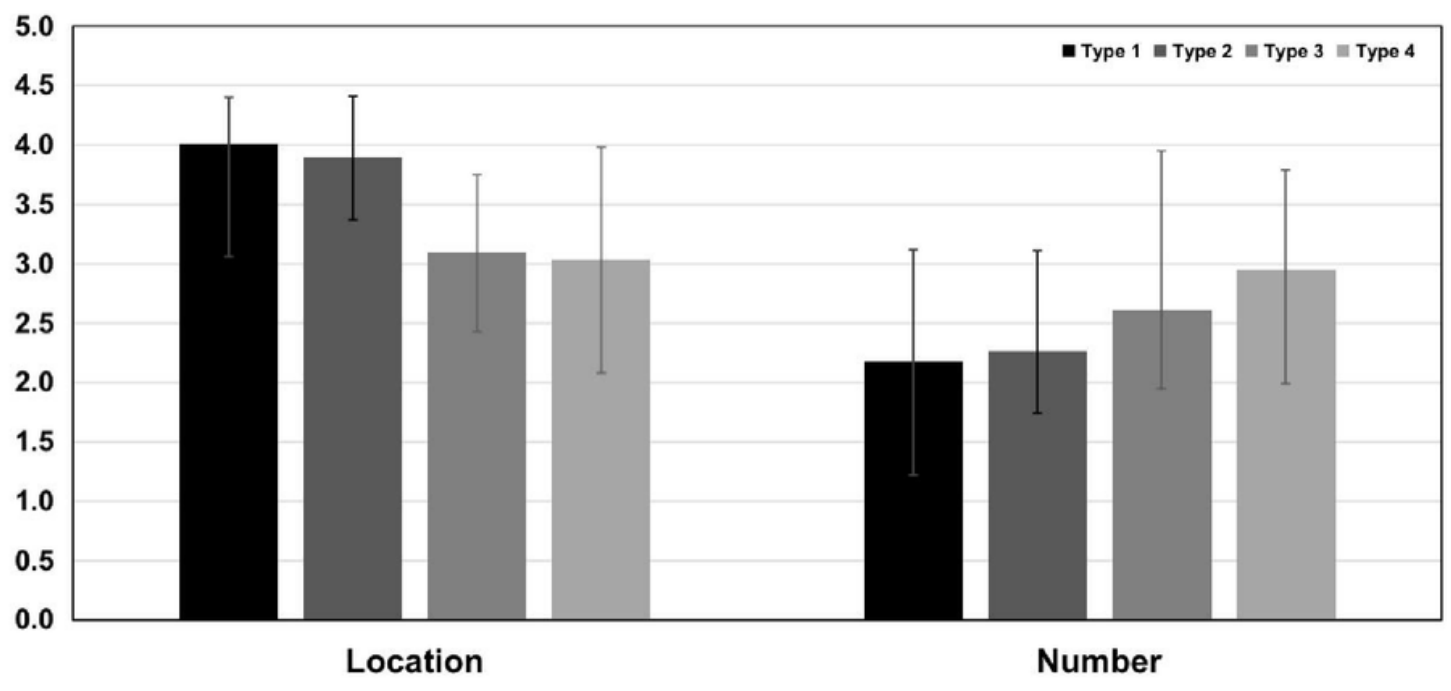

Figure 3

The location and number of the lumbar disc herniation according to the Roussouoly classification in the elderly LDH patients. 


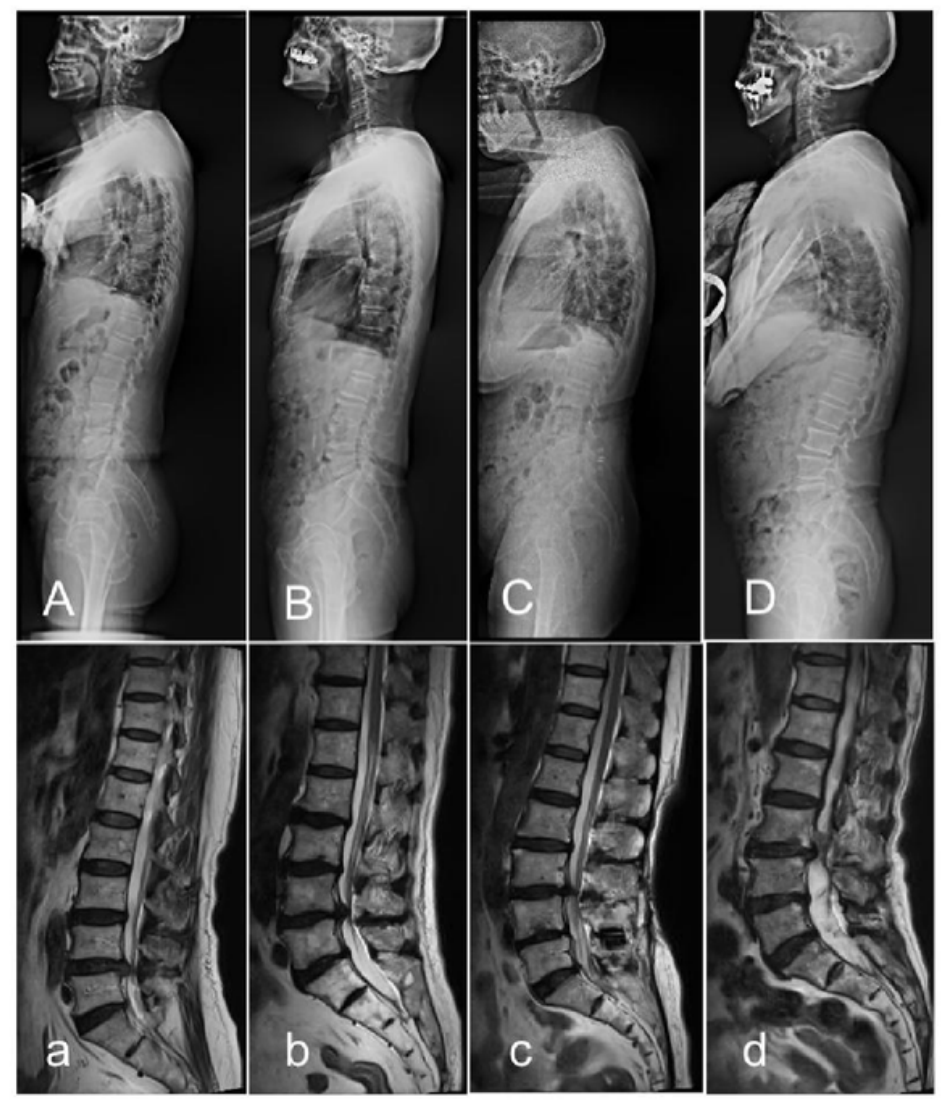

\section{Figure 4}

Full spine lateral radiographs A, B, C, D show four Roussouly types. Meanwhile, T2 sagittal magnetic resonance imaging (MRI) a, b, c, d show the level of disc herniation accordingly. 